\title{
TRIBOLOGICAL PROPERTIES OF THERMALLY SPRAYED WC CERMET COATING UNDER EXTREME OPERATING CONDITIONS
}

\author{
D. M. Nuruzzaman ${ }^{1 *}$, Akira Nakajima ${ }^{2}$ and Toshifumi Mawatari ${ }^{2}$ \\ Department of Mechanical Engineering \\ ${ }^{1}$ Dhaka University of Engineering and Technology, Gazipur-1700, Bangladesh \\ ${ }^{2}$ Faculty of Science and Engineering, Saga University, 1, Honjo-machi, Saga-shi, Saga 840-8502, Japan \\ *E-mail: dewan052005@yahoo.com
}

\begin{abstract}
In this study, tribological properties of thermally sprayed WC-Cr-Ni cermet coating were investigated experimentally under lubricated rolling with sliding contact conditions. Hi-HVOF sprayed WC cermet coatings were deposited onto the axially ground, blasted and circumferentially ground roller specimens made of carburized hardened steel. Under extreme operating conditions such as contact pressure $P_{H}=1.4 \mathrm{GPa}$, slip ratio $s=-28.0 \%$ and mating surface roughness $R_{\max }=6.0 \mu \mathrm{m}$, the effects of substrate surface finish on the tribological properties of the cermet coating were examined. It was found that cermet coating showed a long life and durability was not influenced by the substrate surface finish. It was also found that coefficient of friction, oil film formation, surface temperature and oil film thickness were not much influenced by the substrate surface finish. On the other hand, surface hardness, surface roughness and coating material loss were significantly influenced depending on the substrate surface finish.
\end{abstract}

Keywords: Substrate surface finish, Tribological properties, WC-Cr-Ni cermet

\section{INTRODUCTION}

In recent years, the quality and reliability of thermally sprayed coatings have been improved remarkably to satisfy the growing needs of the market for high wear resistance of engineering components. This is due to the development of new processes so that the coating deposition system can be designed to optimize the velocity and temperature of the spray particles or due to the introduction of advanced techniques such as application of heat sources with higher energy and controlling the spray parameters. Among the cermet coatings, the most attractive proved to be the hard coatings of tungsten carbide (WC) based cermets because of its excellent tribological properties ${ }^{1}$. These cermet coatings can be prepared by the conventional type high velocity oxy-fuel flame spraying (HVOF) and the high energy type flame spraying (Hi-HVOF) processes ${ }^{2}$. The resulting coatings are durable in wear applications due to their high hardness and low porosity. However, the investigations on the tribological properties of these thermally sprayed cermet coatings under rolling with sliding contact conditions are limited ${ }^{3-5}$.

The effects of coating thickness and slip ratio on durability of HVOF sprayed WC-Cr-Ni cermet coating were investigated under lubricated rolling/sliding contact conditions $^{6}$. It was found that durability of cermet coating was significantly influenced by the slip ratio and coating thickness. The influence of spray parameters on the particle in-flight properties and coating properties during $\mathrm{HVOF}$ spraying of WC cermet powder was investigated ${ }^{7}$. It was found that the spray parameters such as the total gas flow rate, the powder feed rate and the spray distance influenced the particle properties and the coating properties to different degrees. Surface durability of WC cermet coating was investigated under lubricated rolling with sliding contact $^{8}$. It was found that durability was significantly influenced by the substrate surface finish. Surface durability of WC cermet coated steel roller was examined under rolling with sliding contact and it was found that durability or life to flaking of coated roller was greatly influenced by the substrate material ${ }^{9}$. Durability and tribological properties of thermally sprayed WC cermet coating in full film and partial EHL contacts were investigated $^{10}$. It was found that in general, the coating on the circumferentially ground substrate shows a lower durability compared with that on the axially ground substrate and this difference appears more distinctly for the higher contact pressure for both full film and partial EHL conditions. It was also found that there are significant differences in the tribological properties of WC cermet coating depending on the contact pressure. In addition, depending on the lubrication condition, remarkable differences in the tribological properties were found. Characteristics of thermally sprayed WC cermet coating under lubricated rolling with sliding contact were also investigated $^{11}$. In general, durability of cermet coating was significantly influenced depending on the mating surface roughness, substrate material, coating thickness and substrate surface finish. On the other hand, coefficient of friction, surface roughness and depth of flaking were markedly influenced depending on the mating surface roughness.

In the present research, tribological properties of thermally sprayed WC-Cr-Ni cermet coating were investigated experimentally under lubricated rolling with sliding contact conditions. Coatings were deposited onto the axially ground, blasted and circumferentially ground roller specimens made of carburized hardened steel. Under extreme operating conditions, the effects of substrate surface finish on durability, coefficient of friction, oil film formation, surface temperature and oil film thickness were investigated. In addition, the effects of substrate surface finish on surface hardness, surface roughness and coating material loss were also examined.

\section{EXPERIMENTAL DETAIL}

Test specimen (coated roller) and mating non-coated roller:

The substrate material of the test specimen is a carburized hardened steel and the coating material is $\mathrm{WC}$ $\mathrm{Cr}-\mathrm{Ni}$ cermet. Chemical compositions of the substrate material and the coating material are shown in Table 1 . The material of the mating non-coated roller is same as the substrate material of the coated roller. 
Table 1: Chemical composition (by mass $\%$ ) of test specimen (Coated roller)

\begin{tabular}{|c|c|c|c|c|c|c|c|c|c|}
\hline \multirow{2}{*}{ Carburized hardened steel (substrate) } & $\mathbf{F e}$ & $\mathbf{C}$ & $\mathbf{S i}$ & $\mathbf{M n}$ & $\mathbf{P}$ & $\mathbf{S}$ & $\mathbf{C u}$ & $\mathbf{M o}$ & $\mathbf{C r}$ \\
\cline { 2 - 9 } & Balance & 0.18 & 0.30 & 0.90 & 0.01 & 0.03 & 0.10 & 0.35 & 1.25 \\
\hline \multirow{2}{*}{ Thermally sprayed coating } & \multicolumn{3}{|c|}{ WC } & \multicolumn{3}{c|}{ Cr } & \multicolumn{3}{c|}{$\mathrm{Ni}$} \\
\cline { 2 - 8 } & \multicolumn{3}{|c|}{ Balance } & \multicolumn{3}{c|}{7} \\
\hline
\end{tabular}

Table 2: Spraying conditions

\begin{tabular}{|l|c|c|}
\hline \multicolumn{2}{|c|}{ Spraying process } & Hi-HVOF \\
\hline \multirow{2}{*}{ Pressure, $\mathrm{MPa}$} & Oxygen & 1.0 \\
\cline { 2 - 3 } & Fuel* & 0.9 \\
\hline \multirow{2}{*}{ Flow rate, $\mathrm{m}^{3} / \mathrm{h}$} & Oxygen & 53.6 \\
\cline { 2 - 3 } & Fuel $^{*}$ & 0.02 \\
\hline Sprayed distance, $\mathrm{mm}$ & & 380 \\
\hline Velocity of coating particles, $\mathrm{m} / \mathrm{s}$ & 1080 \\
\hline Velocity of gas, $\mathrm{m} / \mathrm{s}$ & & 2160 \\
\hline
\end{tabular}

- Fuel: Kerosene

Table 3: Specifications of the coated and the non-coated rollers

Diameter of the coated and the non-coated rollers, $\mathrm{mm}$

Micro-Vickers hardness of the coated (Hi-HVOF) roller, HV

Micro-Vickers hardness of the substrate (Carburized hardened), HV

Micro-Vickers hardness of the non-coated roller, HV

Maximum surface roughness of the substrate, $\mu \mathrm{m}$

Maximum surface roughness of the coated roller, $\mu \mathrm{m}$

Maximum surface roughness of the non-coated roller, $\mu \mathrm{m}$

Effective track width in line contact condition, $\mathrm{mm}$

Coating thickness, $\mu \mathrm{m}$

\begin{tabular}{|c|}
60 \\
1100 \\
760 \\
780 \\
7.0 \\
0.2 \\
6.0 \\
10 \\
60 \\
\hline
\end{tabular}

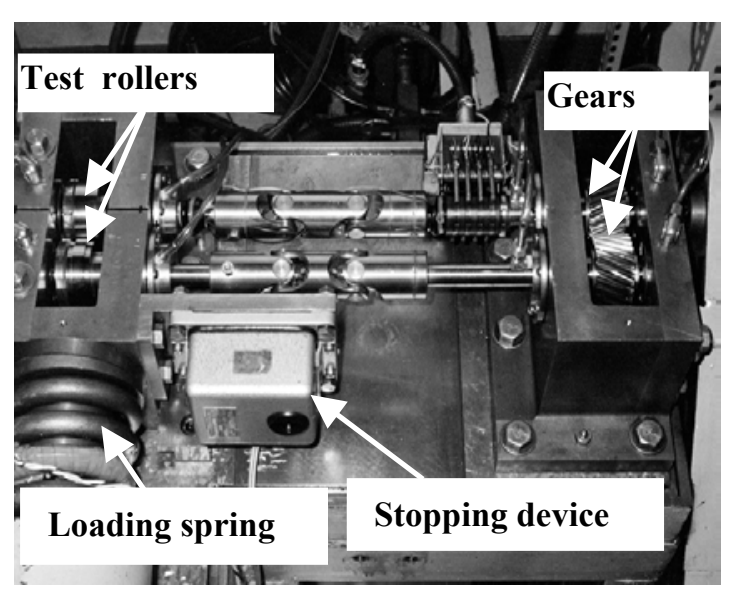

Figure 1: Two-roller testing machine

Substrate surface preparation and thermal spraying conditions:

Before applying the thermally sprayed coating onto the carburized hardened steel substrate, the substrate surface was prepared so that coating material can adhere with the substrate material. Three types of substrate surfaces were prepared by axially grinding, shot-blasting and circumferential grinding. After surface preparation, the maximum surface roughness was $\mathrm{R}_{\max }=7.0 \mu \mathrm{m}$. After that, WC-Cr-Ni cermet coating was formed onto the axially ground, blasted and circumferentially ground roller specimens by means of the high energy type flame spraying (Hi-HVOF) and the spraying conditions are shown in Table 2.

\section{Specifications of rollers:}

WC-Cr-Ni cermet coating of about $60 \mu \mathrm{m}$ in thickness was prepared. After spraying, the contact surface of coated roller was finished smooth to a mirror-like condition with a maximum surface roughness $R_{\max }=0.2 \mu \mathrm{m}$ by grinding and subsequent polishing. The micro-Vickers hardness of the coating formed by Hi-HVOF was $\mathrm{HV} \approx 1100$ (test load: 2.94 Newton). The maximum surface roughness of noncoated roller was $R_{\max }=6.0 \mu \mathrm{m}$. The detail specifications of coated roller and mating non-coated roller are shown in Table 3.

Testing machine, test conditions and lubricating oil:

Using a two-roller testing machine shown in Figure 1, experiments were carried out to investigate the tribological properties of thermally sprayed WC-Cr-Ni cermet coating under lubricated rolling with sliding contact conditions. In the experiments, using a coil spring the normal load was applied in line contact condition. The normal load which gives the Hertzian contact pressure $\mathrm{P}_{\mathrm{H}}=1.4 \mathrm{GPa}$ was applied. Moreover, under rolling with sliding contact condition, using the gear ratio $25 / 32$, a slip ratio, $\mathrm{s}=$ $28.0 \%$ was applied. An automatic stopping device was attached with the testing machine and this device worked in response to any abnormal vibration induced by the occurrence of flaking/delamination of coating. In the experiments, durability or life to flaking of coating $\mathrm{N}$ is defined as the total number of revolutions of the coated roller. When the testing machine continued to run without any flaking of the coating, the running was discontinued at $\mathrm{N}=2.0 \times 10^{7}$ cycles. As lubricant, a paraffinic mineral oil without extreme pressure (EP) additives (kinematic viscosity v: $62.9 \mathrm{~mm}^{2} / \mathrm{s}$ at $313 \mathrm{~K}, 8.5 \mathrm{~mm}^{2} / \mathrm{s}$ at $373 \mathrm{~K}$, pressure-viscosity coefficient $\alpha: 13.3 \mathrm{GPa}-1$ at $313 \mathrm{~K}$ ) was supplied at a flow rate of $15 \mathrm{~cm}^{3} / \mathrm{s}$ and at a constant oil temperature of $318 \mathrm{~K}$. The state of oil film formation with the number of cycles was measured by means of an electrical resistance method ${ }^{12}$, and the friction force between coated roller and non-coated roller was measured by strain gauges. 


\section{RESULTS AND DISCUSSION}

Figure 2 exhibits the effect of substrate surface finish on durability or life to flaking of WC cermet coating under extreme operating conditions such as contact pressure $\mathrm{P}_{\mathrm{H}}=$ $1.4 \mathrm{GPa}$, slip ratio $\mathrm{s}=-28.0 \%$ and mating surface roughness $\mathrm{R}_{\max }=6.0 \mu \mathrm{m}$. The substrate material was carburized hardened steel. From the figure it can be seen that the coating on the axially ground substrate showed a high durability and it showed a long life over $\mathrm{N}=2.0 \times 10^{7}$ cycles. It can also be observed that in the case of blasted or circumferentially ground substrate, coating showed a long life and it was possible to run over $\mathrm{N}=2.0 \times 10^{7}$ cycles.

Figure 3 illustrates the effect of substrate surface finish on change in the coefficient of friction with the number of cycles under a contact pressure $\mathrm{P}_{\mathrm{H}}=1.4 \mathrm{GPa}$, slip ratio $\mathrm{s}=-28.0 \%$ and mating surface roughness $\mathrm{R}_{\max }=$ $6.0 \mu \mathrm{m}$. From the figure, it can be seen that in the case of axially ground substrate and at the start of running, coefficient of friction was about 0.06 and it decreased very slowly with the number of cycles and came to a steady value about 0.05 within a short time. From the figure, it can also be noticed that the change in the coefficient of friction with the number of cycles followed almost the same trend when the substrate surface was blasted or circumferentially ground. From the obtained results, it was confirmed that coefficient of friction was hardly influenced by the substrate surface finish. However, it could be considered that there was a very little difference in the coefficient of friction during running-in depending on the running conditions.

Figure 4 shows the effect of substrate surface finish on change in the electrical contact voltage with the number of cycles under the operating conditions as before. These results were the measurements of the state of oil film formation using the electrical contact resistance method. During running-in, the variations of average electrical contact voltage which corresponds to the changes in the electrical contact resistance arising from the formation/breakdown of oil film were plotted. In the measurements, contact voltage $=0 \mathrm{mV}$ means metal-tometal contact, while contact voltage $=15 \mathrm{mV}$ means complete separation of the surfaces by oil film. As is apparent from the figure and in the case of axially ground substrate, at the very early stage of running, the separation voltage was very near to zero or extremely low value and it increased steadily with the number of cycles. From the figure it can also be observed that formation of oil film followed almost the same trend when the substrate surface

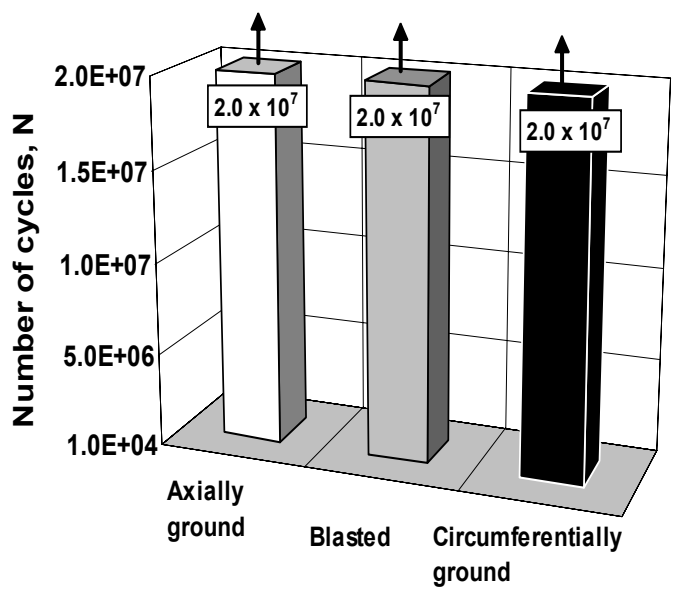

Figure 2: Effect of substrate surface finish on durability or life to flaking of WC Cermet coating $\left(\mathrm{R}_{\max }=6.0 \mu \mathrm{m}\right)$.

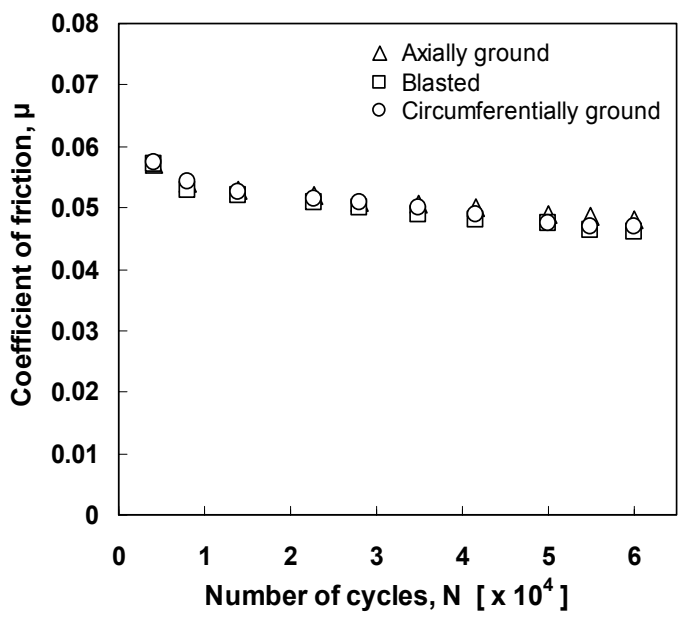

Figure 3: Effect of substrate surface finish on change in the coefficient of friction $\left(\mathrm{R}_{\max }=6.0 \mu \mathrm{m}\right)$.

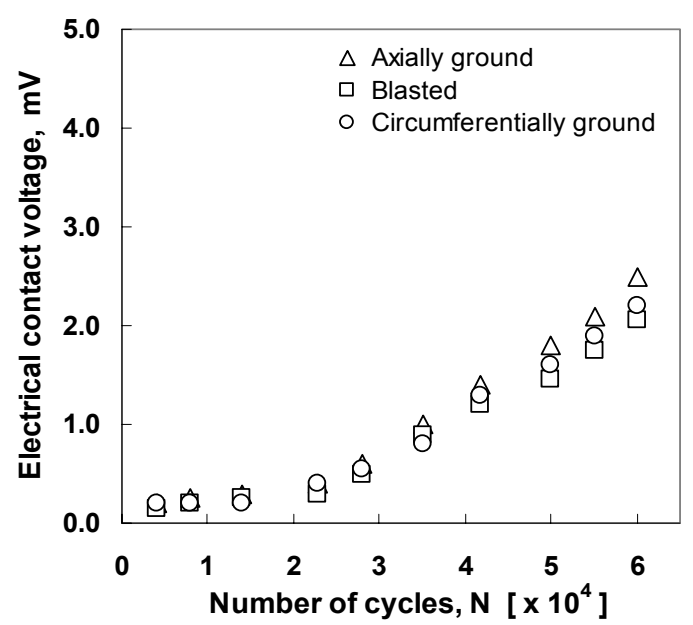

Figure 4: Effect of Substrate Surface Finish on Change in the Electrical Contact Voltage $\left(\mathrm{P}_{\mathrm{H}}=1.4 \mathrm{GPa}, \mathrm{s}=-28.0 \%\right.$, $\left.\mathrm{R}_{\max }=6.0 \mu \mathrm{m}\right)$.

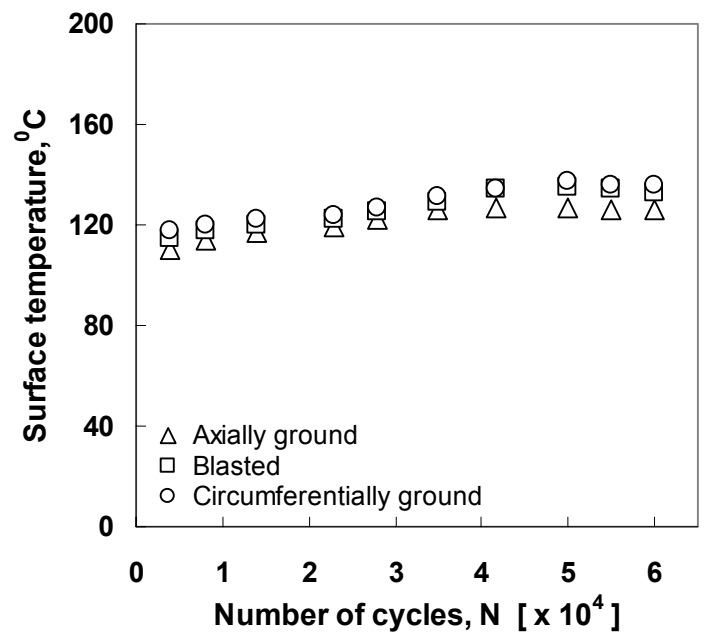

Figure 5: Effect of substrate surface finish on surface temperature $\left(\mathrm{P}_{\mathrm{H}}=1.4 \mathrm{GPa}, \mathrm{s}=-28.0 \%, \mathrm{R}_{\max }=6.0 \mu \mathrm{m}\right)$.

was blasted or circumferentially ground. From the obtained results, it could be considered that oil film formation was hardly influenced by the substrate surface finish. However, there was a very little difference in the state of oil film 
formation during running-in depending on the running conditions.

Figure 5 shows the effect of substrate surface finish on surface temperature of WC cermet coated roller. From the figure, it is apparent that in the case of axially ground substrate, at the start of running, the surface temperature was about $110^{\circ} \mathrm{C}$ and it increased very steadily with the number of cycles and came to a constant value about $125^{\circ} \mathrm{C}$ within a short time. It can also be seen that surface temperature was slightly higher when the substrate surface was blasted or circumferentially ground and change in surface temperature followed almost the same trend as before. The obtained results revealed that surface temperature was slightly influenced by the substrate surface finish.

Figure 6 represents the effect of substrate surface finish on oil film thickness under the operating conditions as before. From the figure, it can be observed that in the case of axially ground substrate and during the running-in process, the oil film thickness was about $0.16 \mu \mathrm{m}$. From the figure, it can also be seen that in the case of blasted or circumferentially ground substrate oil film thickness was about $0.12 \mu \mathrm{m}$ which is slightly lower than that in the case of axially ground substrate. From the obtained results it can be concluded that oil film thickness was slightly influenced by the substrate surface finish.

Figure 7 exhibits the effect of substrate surface finish on surface hardness of the WC cermet coating. From the figure, it can be observed that before the test, hardness of coated surface was about $1070 \mathrm{HV}$ and after the test, surface hardness was increased. Namely, in the case of axially ground or blasted substrate, after the test, hardness of the coated surface became about $1200 \mathrm{HV}$. On the other hand, in the case of circumferentially ground substrate, after the test, hardness of the coated surface was much increased and it became about $1260 \mathrm{HV}$. From these results it is apparent that during the running-in process, work hardening of the coated surface occurred and surface hardness of the coating was much more increased in the case of circumferentially ground substrate than that in the case of axially ground or blasted substrate.

Figure 8 shows the effect of substrate surface finish on surface roughness of WC cermet coated roller. In the experiments, the coated carburized hardened steel roller was mated with the non-coated carburized hardened steel roller. From the figure, it can be seen that in the case of axially ground substrate, before experiment, the surface roughness of coated roller was about $0.2 \mu \mathrm{m}$ and after experiment, the surface roughness was greatly increased and it became about $2.0 \mu \mathrm{m}$. In the case of blasted substrate, after experiment, the surface roughness of the coated roller was also significantly increased and it became about $3.0 \mu \mathrm{m}$. From the figure it is apparent that in the case of circumferentially ground substrate, before experiment, the surface roughness of coated roller was about $0.2 \mu \mathrm{m}$ whereas after experiment, the surface roughness of coated roller was remarkably increased and it became about $4.0 \mu \mathrm{m}$. The obtained results revealed that after running, roughness of the coated surface was much more influenced in the case of circumferentially ground substrate than that in the case of axially ground or blasted substrate.

Figure 9 demonstrates the effect of substrate surface finish on material loss of $\mathrm{WC}$ cermet coating. In the experiments, the coated carburized hardened steel roller was mated with the non-coated carburized hardened steel roller. From the figure, it can be seen that after the running- in process, the coating material loss was $0.01 \mathrm{gm}$ in the case of axially ground substrate. It can also be observed that in the case of blasted substrate, the coating material loss was $0.02 \mathrm{gm}$ and in the case of circumferentially ground substrate, it was $0.03 \mathrm{gm}$. From these results, it is

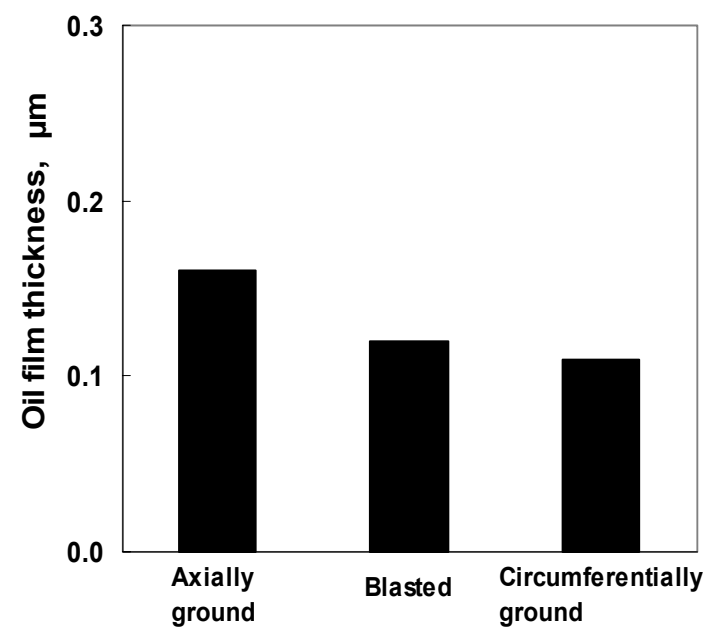

Figure 6: Effect of substrate surface finish on oil film thickness $\left(\mathrm{P}_{\mathrm{H}}=1.4 \mathrm{GPa}, \mathrm{s}=-28.0 \%, \mathrm{R}_{\max }=6.0 \mu \mathrm{m}\right)$.

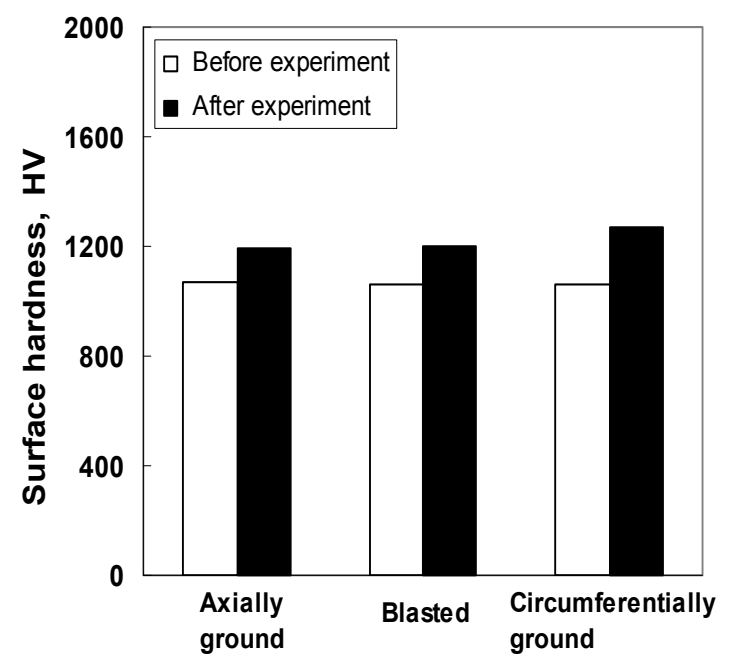

Figure 7: Effect of substrate surface finish on surface hardness $\left(\mathrm{P}_{\mathrm{H}}=1.4 \mathrm{GPa}, \mathrm{s}=-28.0 \%, \mathrm{R}_{\max }=6.0 \mu \mathrm{m}\right)$.

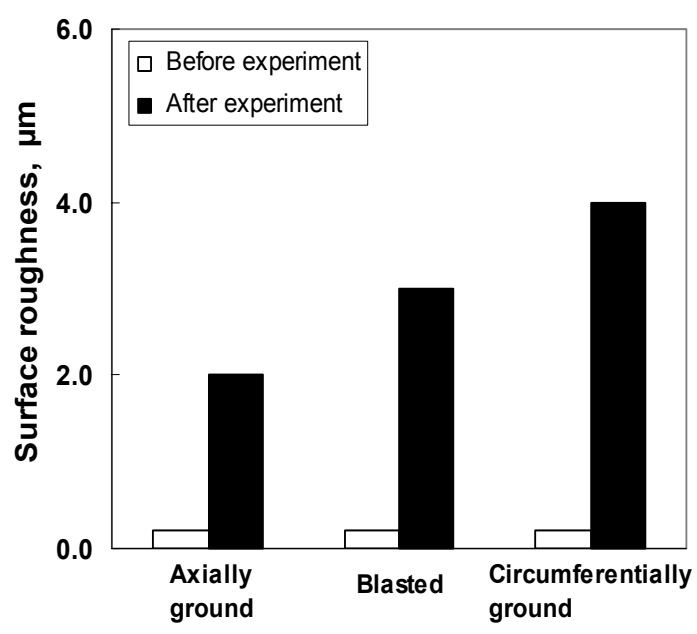

Figure 8: Effect of substrate surface finish on surface roughness $\left(\mathrm{P}_{\mathrm{H}}=1.4 \mathrm{GPa}, \mathrm{s}=-28.0 \%, \mathrm{R}_{\max }=6.0 \mu \mathrm{m}\right)$. 


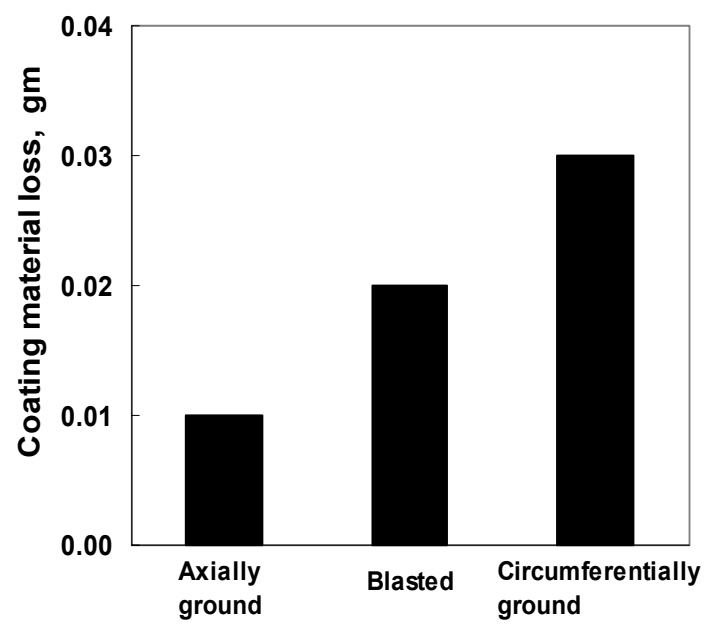

Figure 9: Effect of substrate surface finish on coating material loss $\left(\mathrm{P}_{\mathrm{H}}=1.4 \mathrm{GPa}, \mathrm{s}=-28.0 \%, \mathrm{R}_{\max }=6.0 \mu \mathrm{m}\right)$.

apparent that the loss of coating material was higher in the case of circumferentially ground substrate than that in the case of axially ground or blasted substrate.

\section{CONCLUSION}

In this study, tribological properties of thermally sprayed WC-Cr-Ni cermet coating were investigated under extreme operating conditions. The substrate material was carburized hardened steel. The effects of substrate surface finish on the tribological properties of the cermet coating were examined. The obtained results are summarized to give the following conclusions:

Cermet coating showed a high durability and it was found that life of the coating was not influenced by the substrate surface finish.

Coefficient of friction, oil film formation and surface temperature were hardly influenced by the substrate surface finish. Oil film thickness was slightly influenced by the substrate surface finish.

After the running-in process, surface hardness of the coating was much more increased in the case of circumferentially ground substrate than that in the case of axially ground or blasted substrate. Moreover, surface roughness of the coating was significantly influenced depending on the substrate surface finish.

After the running-in process, the loss of coating material was higher in the case of circumferentially ground substrate than that in the case of axially ground or blasted substrate.

\section{REFERENCES}

[1] Knapp, J. K. and Nitta, H., 1997, "Fine-Particle Slurry Wear Resistance of Selected Tungsten Carbide Thermal Spray Coatings," Tribology International, Vol. 30, pp. 225-234.

[2] Tani, K., Nakahira, H., Miyajima, K. and Harada, Y., 1992, "Thermal and Elastic Anisotropy of Thermally Sprayed Coatings," Material Transaction, Japan Institute of Metals, Vol. 33, pp. 618-626.

[3] Ahmed, R. and Hadfield, M., 1997, "Wear of High Velocity Oxy-fuel (HVOF)-Coated Cones in Rolling Contact", Wear, Vol. 203-204, pp. 98-106.
[4] Ahmed, R. and Hadfield, M., 1997, "Rolling Contact Fatigue Performance of Detonation Gun Coated Elements", Tribology International, Vol. 30, pp. 129137.

[5] Ahmed, R. and Hadfield, M., 1996, "Rolling Contact Fatigue Behavior of Thermally Sprayed Rolling Elements", Surface and Coatings Technology, Vol. 82, pp. 176-186.

[6] Nakajima, A., Mawatari, T., Yoshida, M., Tani, K. and Nakahira, A., 2000, "Effects of Coating Thickness and Slip Ratio on Durability of Thermally Sprayed WC Cermet Coating in Rolling/Sliding Contact,", Wear, Vol. 241, pp.166-173.

[7] Zhao, L., Maurer, M., Fischer, F., Dicks, R. and Lugscheider, E., 2004, "Influence of Spray Parameters on the Particle In-flight Properties and the Properties of HVOF Coating of WC-CoCr," Wear, Vol. 257, pp. 41-46.

[8] Nakajima, A., Nuruzzaman, D. M., Mawatari, T. and Yoshida, M., 2005, "Effect of Substrate Surface Finish on Durability of Thermally Sprayed WC Cermet Coating under Rolling/Sliding Contact," Japanese Journal of Tribology, Vol. 50(4), pp. 437448.

[9] Nuruzzaman, D. M., Nakajima, A. and Mawatari, T., 2006, "Effects of Substrate Surface Finish and Substrate Material on Durability of Thermally Sprayed WC Cermet Coating in Rolling with Sliding Contact," Tribology International, Vol. 39(7), pp.678685.

[10] Nuruzzaman, D. M., Nakajima, A. and Mawatari, T., 2006, "Durability and Tribological Properties of Thermally Sprayed WC Cermet Coating in Full Film and Partial EHL Contacts," Journal of Mechanical Engineering, Transaction of Mech. Eng. Div., The Institution of Engineers, Bangladesh, Vol. ME36, pp.38-43.

[11] Nuruzzaman, D. M., Nakajima, A. and Mawatari, T., 2007, "Characteristics of Thermally Sprayed WC Cermet Coating under Lubricated Rolling with Sliding Contact," Journal of Mechanical Engineering, Transaction of Mech. Eng. Div., The Institution of Engineers, Bangladesh, Vol. ME37, pp.18-23.

[12] Ichimaru, K., Nakajima, A. and Hirano, F., 1981, "Effect of Asperity Interaction on Pitting in Rollers and Gears," ASME Journal of Mechanical Design, Vol. 103, pp. 482-491. 